\title{
Heterogeneous Responses to Antioxidants in Noradrenergic Neurons of the Locus Coeruleus Indicate Differing Susceptibility to Free Radical Content
}

\author{
Ramatis B. de Oliveira, Fernanda S. Gravina, Rebecca Lim, Alan M. Brichta, \\ Robert J. Callister, and Dirk F. van Helden
}

School of Biomedical Sciences and Pharmacy, The University of Newcastle and Hunter Medical Research Institute, University Drive, Newcastle, NSW 2308, Australia

Correspondence should be addressed to Dirk F. van Helden, dirk.vanhelden@newcastle.edu.au

Received 13 January 2012; Revised 24 January 2012; Accepted 8 February 2012

Academic Editor: Daniel Pens Gelain

Copyright (C) 2012 Ramatis B. de Oliveira et al. This is an open access article distributed under the Creative Commons Attribution License, which permits unrestricted use, distribution, and reproduction in any medium, provided the original work is properly cited.

The present study investigated the effects of the antioxidants trolox and dithiothreitol (DTT) on mouse Locus coeruleus (LC) neurons. Electrophysiological measurement of action potential discharge and whole cell current responses in the presence of each antioxidant suggested that there are three neuronal subpopulations within the LC. In current clamp experiments, most neurons $(55 \% ; 6 / 11)$ did not respond to the antioxidants. The remaining neurons exhibited either hyperpolarization and decreased firing rate $(27 \% ; 3 / 11)$ or depolarization and increased firing rate $(18 \% ; 2 / 11)$. Calcium and JC-1 imaging demonstrated that these effects did not change intracellular $\mathrm{Ca}^{2+}$ concentration but may influence mitochondrial function as both antioxidant treatments modulated mitochondrial membrane potential. These suggest that the antioxidant-sensitive subpopulations of LC neurons may be more susceptible to oxidative stress (e.g., due to ATP depletion and/or overactivation of $\mathrm{Ca}^{2+}$-dependent pathways). Indeed it may be that this subpopulation of LC neurons is preferentially destroyed in neurological pathologies such as Parkinson's disease. If this is the case, there may be a protective role for antioxidant therapies.

\section{Introduction}

Oxidative stress in neurons arises because of an imbalance between free radical production and antioxidant control. This process leads to cell damage and, when severe, can trigger apoptosis or necrosis [1]. Indeed, such oxidative stress may initiate certain neuropathologies such as Alzheimer's and Parkinson's disease whereby oxidative damage to biomolecules causes cellular dysfunction and neuronal death $[1,2]$.

The exact mechanisms whereby healthy neurons become sensitive to oxidative stress are unknown, and it is also unclear whether antioxidant treatments limit the spread of oxidative damage. For example, it has been reported that varying levels of oxidants can modulate ion channels and consequently effect important neuronal functions such as pacemaking [3-5]. Thus, antioxidant treatments have been developed and used and have indeed had beneficial effects in preventing or slowing the onset of neurological disease [6].

Antioxidants may modulate transcription factors that ultimately lead to oxidative stress [7]. On the other hand, it has been demonstrated that molecules that were thought to be antioxidants due to their antioxidant capacity in vitro (such as vitamin A and retinoids) have different effects in living organisms (in vivo) as they can increase oxidative damage to biomolecules and generate oxidative stress [810]. In fact free radicals are crucial components of many intracellular signalling pathways (for a review see [11]), and an exaggerated decrease in their levels could lead to undesired cellular events. Thus, many factors contribute to the varied effectiveness of antioxidants in both human and 
animal trials including differences in dose and timing of antioxidant administration.

The present paper explores the effect of two different antioxidants (Trolox and DTT) on pacemaking in Locus coeruleus (LC) neurons. These antioxidants can chelate different reactive species. Both compounds are membrane permeable, so they can easily access intracellular compartments. Trolox is a water-soluble vitamin E analogue with a broad antioxidant spectrum [12], whereas DTT is a reducing agent that acts on thiol $(-\mathrm{SH})$ groups [13]. Here, we demonstrate that LC neurons exhibit three different types of electrophysiological responses to these antioxidants. We believe these responses may represent three neuronal populations that have differential sensitivity to free radicals and are involved in the massive loss of LC neurons observed in pathologies such as Parkinson's disease.

\section{Experimental Procedures}

2.1. Preparation of Brain Slices. All procedures used in this study were approved by the University of Newcastle Animal Care and Ethics Committee. Brain slices containing the LC were prepared from Swiss mice (P7-12, both sexes) rendered unconscious with Ketamine (100 mg/kg i.p.) according to a previous established protocol [14]. Mice were decapitated, and the brain was rapidly removed and immersed in icecold "modified sucrose ringer" containing (in $\mathrm{mM}$ ): 25 $\mathrm{NaHCO}_{3}, 11$ Glucose, 235 Sucrose, $2.5 \mathrm{KCl}, 1 \mathrm{NaH}_{2} \mathrm{PO}_{4}$, $1 \mathrm{MgCl}_{2}$, and $2.5 \mathrm{CaCl}_{2}$, bubbled with $95 \% \mathrm{O}_{2} / 5 \% \mathrm{CO}_{2}$ [15]. The cerebellum and brain stem were isolated and slices (270-300 $\mu \mathrm{m}$ thick) were cut with a vibrating tissue slicer (Leica VT1000S). Slices were kept in a recovery chamber (containing ACSF) at room temperature and high oxygen for $1.5-2 \mathrm{~h}$ before experiments commenced. The slice containing the LC was identified and transferred to a recording bath where it was visualized with an upright microscope (Olympus BX50) and superfused with artificial cerebrospinal fluid (ACSF) containing (in mM): $120 \mathrm{NaCl}, 25 \mathrm{NaHCO}_{3}$, 11 Glucose, $2.5 \mathrm{KCl}, 1 \mathrm{NaH}_{2} \mathrm{PO}_{4}, 1 \mathrm{MgCl}_{2}$ and $2.5 \mathrm{CaCl}_{2}$, constantly bubbled with $95 \% \mathrm{O}_{2} / 5 \% \mathrm{CO}_{2}$. LC neurons were visualized using infrared video microscopy with differential interference contrast optics and identified according to their large size and location near the ventrolateral border of the fourth ventricle [16]. Most experiments were performed on neurons in slices, whereas our $\mathrm{Ca}^{2+}$ imaging and JC-1 experiments used isolated LC neurons.

2.2. Preparation of Fresh Dissociated LC Neurons. Neurons were isolated using an adapted protocol according to [17]. Brain slices were cut using the same protocol described above in "Preparation of brain slices" and allowed to recover for $1 \mathrm{~h}$ in the recovery chamber. Slices were then placed in the ACSFcontaining recording chamber, and neurons were dissociated and isolated using a custom-made vibrating device. This instrument dissociated neurons by vibrating a fine glass electrode with a sealed tip just above the tissue surface. This method usually provided about 10 healthy neurons per slice. After isolation, neurons were left for $15 \mathrm{~min}$ to settle on the glass bottom of the recording chamber before gentle ACSF perfusion was commenced.

2.3. Electrophysiology. Electrophysiological recordings were made using the whole cell attached voltage clamp or current clamp recording modes (Axopatch-1C amplifier) with data sampled at $100 \mathrm{kHz}$ and low-pass filtered at $5 \mathrm{kHz}$. Electrodes had resistance ranging from 1.8 to $2.5 \mathrm{M} \Omega$. Neurons were considered to be adequately voltage clamped when no unclamped spikes were observed during voltage ramp application $[14,16]$.

2.4. Solutions and Pharmacology. To avoid perfusionassociated washout during whole cell recording, we used the same experimental protocol as described previously [16]. In brief, $10 \mathrm{~s}$ after intracellular access was obtained, the first voltage protocol was applied, with the treatment perfusion started immediately using a rapid exchange ( $>95 \%$ change over time $\sim 2 \mathrm{~s}$ ) local-perfusion system [18]. The second voltage protocol was then applied $180 \mathrm{~s}$ after commencement of treatment. Total incubation time for voltage clamp experiments was $180 \mathrm{~s}$; the incubation time for other experiments is indicated in the respective figures. Tetrodotoxin (TTX; $1 \mu \mathrm{M}$ ) was added to the perfusate to block voltage-dependent $\mathrm{Na}^{+}$channels when step pulse protocols were applied. The standard internal pipette solution contained (in $\mathrm{mM}$ ): $135 \mathrm{~K}$ methylsulphate, $8 \mathrm{NaCl}, 10$ HEPES, $2 \mathrm{Mg}_{2} \mathrm{ATP}, 0.3 \mathrm{Na}_{3} \mathrm{GTP}$, 0.1 EGTA, pH: 7.3. The standard external solution used was ACSF. All experiments were carried out at $33 \pm 2{ }^{\circ} \mathrm{C}$.

2.5. Acquisition and Analysis. Data were acquired using Axograph 4.8 software (ITC-16 interface and a Mac G4 computer) and analysed using Axograph X 1.1.0 software. Input resistance, cell capacitance, and series resistance were measured by the software according to the response to a $-5 \mathrm{mV}$ pulse delivered shortly after obtaining the whole cell recording mode. A correction of $-8.5 \mathrm{mV}$, calculated using JPCalc [19], was applied to account for the junction potential between ACSF and $\mathrm{K}$ methyl sulphate in the recording pipette. $I-V$ plots were constructed from depolarizing pulse protocol recordings. Individual currents were normalised to cell size based on the whole cell capacitance to obtain current density values $(\mathrm{pA} / \mathrm{pF})$. Current density values were multiplied by 100 to normalise values to the measured current. Recordings obtained by ramp and depolarizing pulse protocols were filtered at $1 \mathrm{kHz}$ using Axograph $\mathrm{X}$ software prior to analysis.

2.6. Measurement of Cytosolic $\mathrm{Ca}^{2+}$ and Mitochondrial Membrane Potential $(\Psi \mathrm{m})$. Relative intracellular $\left[\mathrm{Ca}^{2+}\right]$ or $\Psi \mathrm{m}$ was measured in freshly dissociated LC neurons. After isolation (Methods), LC neurons were incubated in ACSF at room temperature containing the fluophores $10 \mu \mathrm{M}$ Oregon green/AM for $45 \mathrm{~min}$ or $5 \mu \mathrm{g} / \mathrm{mL} \mathrm{JC-1}$ for $1 \mathrm{~h}$ [20]. The recording chamber containing the isolated and loaded neurons was then placed on the stage of a Nikon TE200 inverted microscope connected to a BIORAD 1000 confocal scanner system. The isolated neurons were viewed with a $60 \mathrm{X}$ 


\begin{tabular}{lc|ccc}
\multicolumn{2}{l}{ Impact on spontaneous firing } & \multicolumn{3}{c}{ Action potential values } \\
\hline & $\begin{array}{c}100 \mu \mathrm{M} \\
\text { Trolox }\end{array}$ & & ACSF & $\begin{array}{r}100 \mu \mathrm{M} \\
\text { Trolox }\end{array}$ \\
\hline No effect & 6 of 11 & $\begin{array}{c}\text { AP } \\
\text { amplitude } \\
(\mathrm{mV})\end{array}$ & $92.6 \pm 0.8$ & $89.9 \pm 1.3$ \\
$\begin{array}{l}\text { Increased } \\
\text { (depolarization) }\end{array}$ & 2 of 11 & $\begin{array}{c}\text { AHP } \\
\text { amplitude } \\
(\mathrm{mV})\end{array}$ & $23.1 \pm 0.3$ & $24.4 \pm 0.4$ \\
$\begin{array}{l}\text { Stopped } \\
\text { (hyperpolarization) }\end{array}$ & 3 of 11 & & & \\
\hline
\end{tabular}

(a)

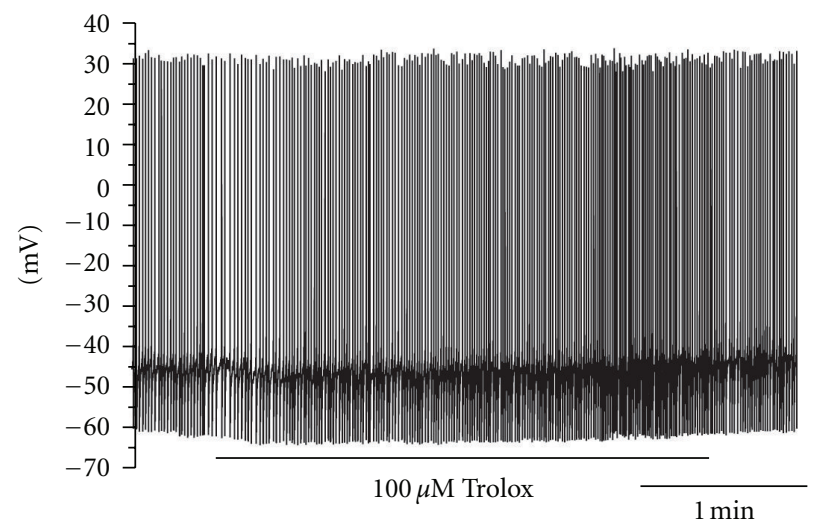

(c)

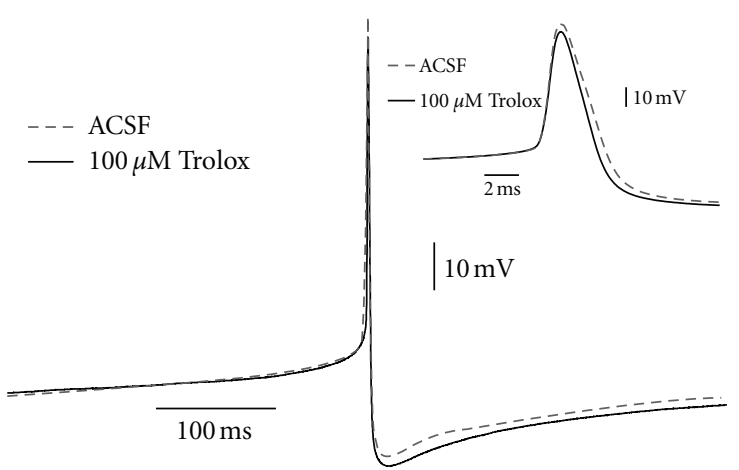

(b)

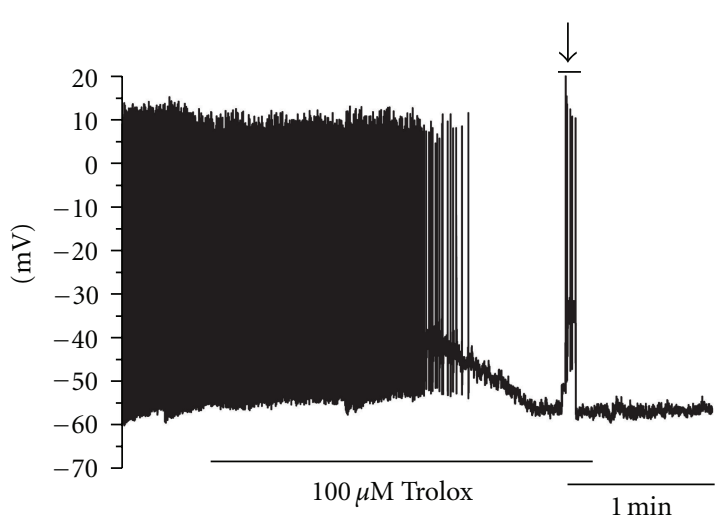

(d)

FIgure 1: Impact of Trolox treatment on pacemaker activity in LC neurons. (a) Table demonstrating the effect of $100 \mu \mathrm{M}$ Trolox on the spontaneous firing of LC neurons and comparison of values obtained for action potentials (APs) before (ACSF) and $180 \mathrm{~s}$ after $100 \mu \mathrm{M}$ Trolox treatment ( $n=11$ for spontaneous firing and $n=23$ for AP comparison). (b) Comparison of the waveshape of averaged APs before (ACSF) and $180 \mathrm{~s}$ after application of $100 \mu \mathrm{M}$ Trolox in ACSF $(n=23)$. Hyperpolarizing group was excluded from comparison demonstrated in a and b due to lack of APs at $180 \mathrm{~s}$ treatment. (c) and (d) Recordings demonstrating opposite effects induced by $100 \mu \mathrm{M}$ Trolox which in a small number of cases depolarized neurons and increased firing (c) or hyperpolarized neurons which led to abolition of AP firing (d) $(n=11)$. AP firing recommenced in response to depolarization induced by current injection (d, Arrow).

water immersion objective. ACSF was perfused for at least 10 min before experiments commenced. The Oregon green fluophore was excited using a $488 \mathrm{~nm} 20 \mathrm{~mW}$ Argon laser with intensity set to $3 \%$ and recordings made using a $522 \mathrm{~nm}$ emission filter. JC-1 experiments were made using the Argon laser set to $1 \%$ intensity with a filter combination of $488 \mathrm{~nm}$ for excitation and $522 \mathrm{~nm}$ for emission to record the green fluorescence and $514 \mathrm{~nm}$ for excitation and $585 \mathrm{~nm}$ for emission to record the red fluorescence. Relative fluorescence plots were analysed offline using ImageJ software.

2.7. Statistics. All data are presented as mean \pm SEM. GraphPad Prism 4.02 was used to prepare graphics. Statistical analysis was performed with SPSS version 17.0 using oneway ANOVA.

\section{Results}

3.1. Effect of Trolox and DTT on Spontaneous Firing and Voltage-Dependent Currents of LC Neurons. We first examined the effects of antioxidants on spontaneous firing in LC neurons. Application of $100 \mu \mathrm{M}$ Trolox had no significant effect on 6 of 11 neurons (Figure 1(a)). Curiously, under the same conditions, 2 neurons increased their firing rate (Figures 1(a) and 1(c)) and 3 neurons exhibited strong hyperpolarization, which abolished spontaneous firing. In such cases firing could be reinstated by repolarizing the membrane potential via current injection (Figures 1(a) and $1(\mathrm{~d})$ ). Comparison of averaged action potentials (APs) from test $(100 \mu \mathrm{M}$ Trolox) and control (ACSF) neurons showed that there were no differences in AP shape after $180 \mathrm{~s}$ of treatment (Figures 1(a) and 1(b)). The electrophysiological properties of neurons that did not respond and those that hyperpolarized were compared to examine whether the hyperpolarizing neurons were damaged. This comparison showed there were no differences in resting membrane potential, input resistance, firing frequency, and after hyperpolarization amplitude. This indicates that the hyperpolarizing neurons were not simply damaged or unhealthy neurons (See Supplementary Table in Supplementary Material available online at doi:10.1155/2012/820285). 


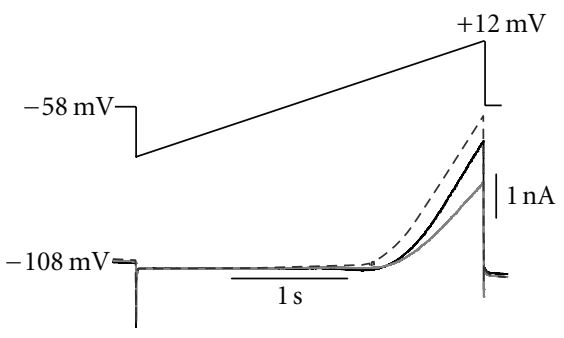

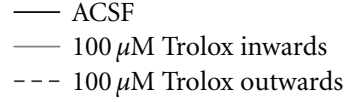

(a)

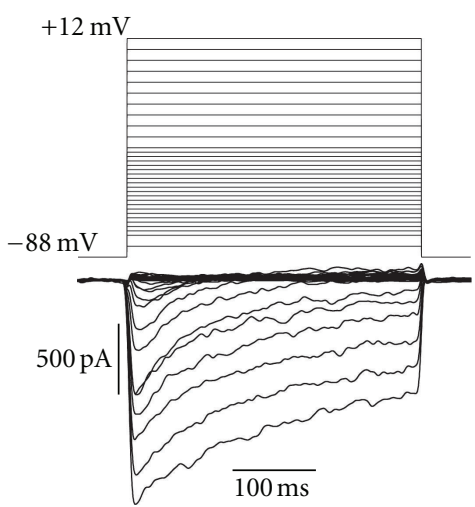

(d)
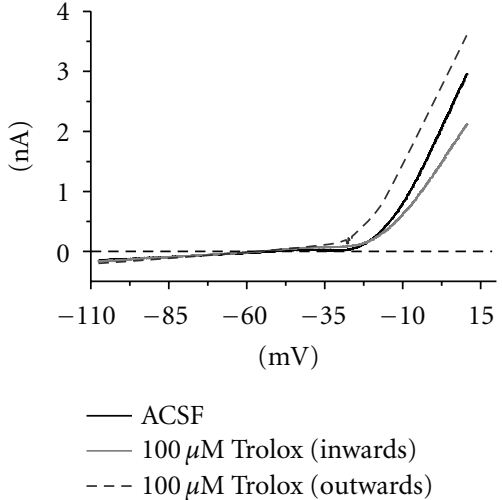

(b)

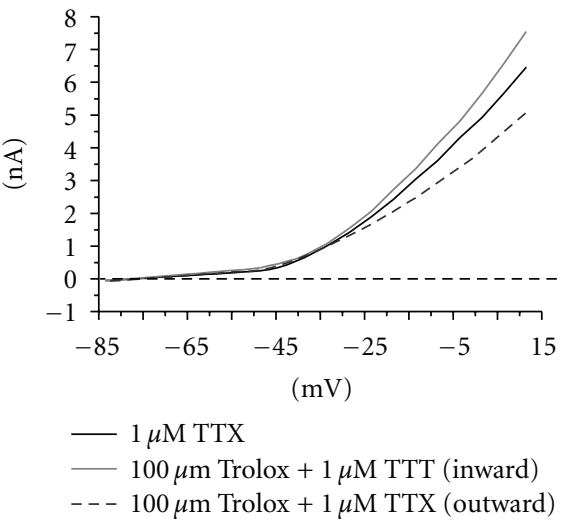

(e)

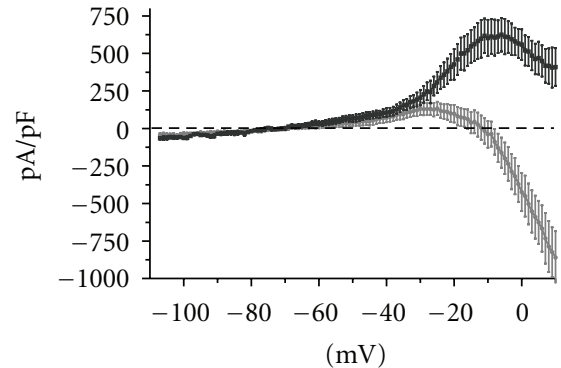

$\rightarrow 100 \mu \mathrm{M}$ Trolox (inward)

- - $100 \mu \mathrm{M}$ Trolox (outward)

(c)

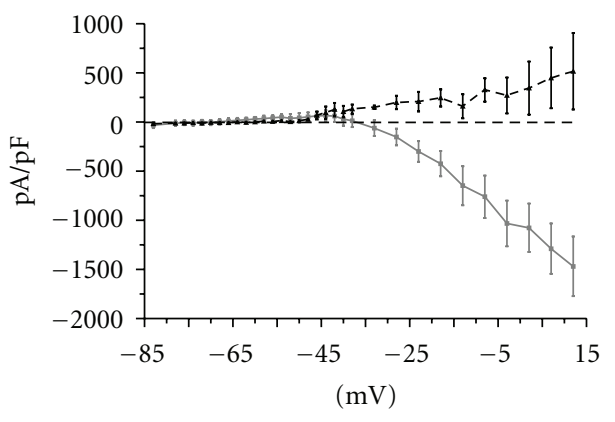

$\longrightarrow 100 \mu \mathrm{M}$ Trolox (inward)

- $100 \mu \mathrm{M}$ Trolox (outward)

(f)

FIGURE 2: Effect of Trolox treatment in voltage-dependent currents evoked by ramps and pulses. (a) Representative recording of the currents evoked by depolarizing ramps showing the current evoked in ACSF (control solution; solid black line) and the inward (solid light grey) and outward (dashed grey) currents evoked at $180 \mathrm{~s}$ after $100 \mu \mathrm{M}$ Trolox application $(n=14)$. (b) $I$ - $V$ plot for the currents presented in (a). (c) Mean differential (i.e., Trolox-control) with records obtained $180 \mathrm{~s}$ after rapid application of Trolox showing the inward (solid light grey, 8 of 14 neurons) and outward (dashed grey, 6 of 14 neurons) currents. (d), (e), and (f) were performed in $1 \mu \mathrm{M}$ TTX background. (d) Representative depolarizing pulse-evoked differential currents obtained by taking the currents in test solution (i.e., $100 \mu \mathrm{M}$ Trolox $+1 \mu \mathrm{M}$ TTX) and subtracting the corresponding currents in control (i.e., $1 \mu \mathrm{M}$ TTX) $180 \mathrm{~s}$ after Trolox application. (e) Averaged $I$ - $V$ plot showing the currents evoked by pulses for control ( $1 \mu \mathrm{M}$ TTX — solid black) and the inward (solid light grey) and outward (dashed grey) currents after $180 \mathrm{~s}$ of $100 \mu \mathrm{M}$ Trolox application. (f) Mean differential $I-V$ plots (i.e., Trolox-TTX) inward (solid light grey, 6 of 8 neurons) and outward (dashed grey, 2 of 8 neurons) after $180 \mathrm{~s}$ application of $100 \mu \mathrm{M}$ Trolox. Graph shows mean \pm SEM with $n=8$ for (d), (e) and (f).

Voltage-dependent currents were first investigated using depolarizing ramps (slope of $40 \mathrm{mV} / \mathrm{s}$ ) that were designed to mimic the natural depolarization during the interspike interval (see [16]). In these experiments ( $n=14$ LC neurons) Trolox induced a heterogeneous response (Figure 2(a)) with 8 neurons presenting a differential outward current followed by an inward current at depolarized potentials. In contrast, the remaining 6 neurons only exhibited a differential outward current (Figures 2(b) and 2(c)). The second protocol applied voltage steps designed to rapidly activate/deactivate a broad range of ionic channels. When this protocol was applied to neurons held at a hyperpolarized potential of $-88 \mathrm{mV}$, similar results were observed, but in this case, more polarized towards the inward current ( 6 of 8 neurons, Figures $2(\mathrm{~d})$ to $2(\mathrm{f}))$. Importantly, the step pulse protocols only generated either an outward or inward current (Figure 2(f)), versus the presence of both currents for ramp protocols
(Figure 2(c)). These results indicate that a mix of different voltage-dependent channels are directly modulated by Trolox and/or by reactive species chelated by this antioxidant, and this effect is heterogeneous within the population of LC neurons.

Dithiothreitol (DTT; $1 \mathrm{mM}$ ) also produced varied effects on spontaneous firing activity of 19 LC neurons (Figure 3(a)). AP firing was not significantly altered in 10 neurons and was abolished in 4 due to marked hyperpolarization (Figure 3(c)), and 3 neurons ceased AP firing with no apparent hyperpolarization (Figures 3(a) and 3(d)). A small portion of the neurons (2/19) increased their AP firing rate after depolarization (2 of 19; Figure 3(a)). AP comparison demonstrated no differences in AP shape (Figure 3(b)) as was the case for Trolox.

The voltage-dependent current responses that were observed after DTT application were more heterogeneous than 


\begin{tabular}{lc|ccc}
\multicolumn{2}{c}{ Impact on spontaneous firing } & \multicolumn{3}{c}{ Action potential values } \\
\hline & 1 mM DTT & & ACSF & $\begin{array}{c}1 \mathrm{mM} \\
\text { DTT }\end{array}$ \\
\hline No effect & 10 of 19 & $\begin{array}{c}\text { AP } \\
\text { amplitude } \\
(\mathrm{mV})\end{array}$ & $95 \pm 1.2$ & $95.9 \pm 1$ \\
$\begin{array}{l}\text { Increased } \\
\text { (depolarization) }\end{array}$ & 2 of 19 & $\begin{array}{c}\text { AHP } \\
\text { amplitude } \\
(\mathrm{mV})\end{array}$ & $24.9 \pm 0.3$ & $26.2 \pm 0.2$ \\
$\begin{array}{l}\text { Stopped } \\
\text { (hyperpolarization) }\end{array}$ & 4 of 12 & & \\
$\begin{array}{l}\text { Stopped (no } \\
\text { hyperpolarization) }\end{array}$ & 3 of 12 & & \\
\hline
\end{tabular}

(a)

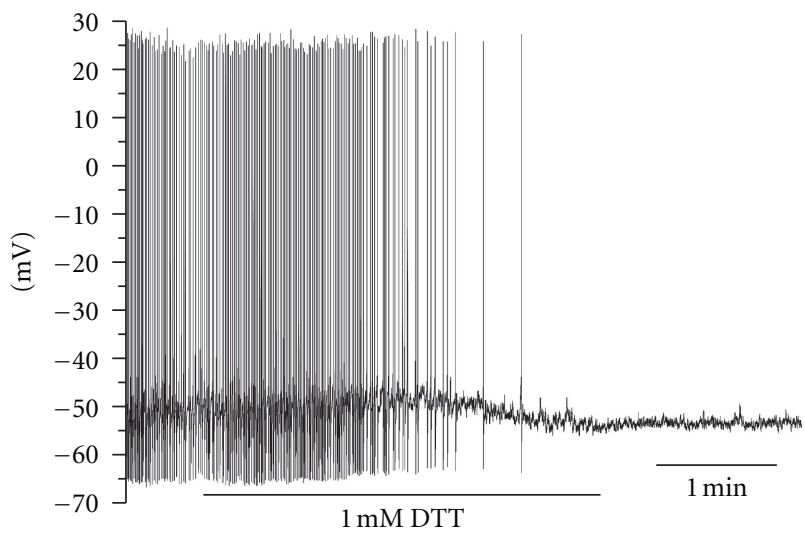

(c)

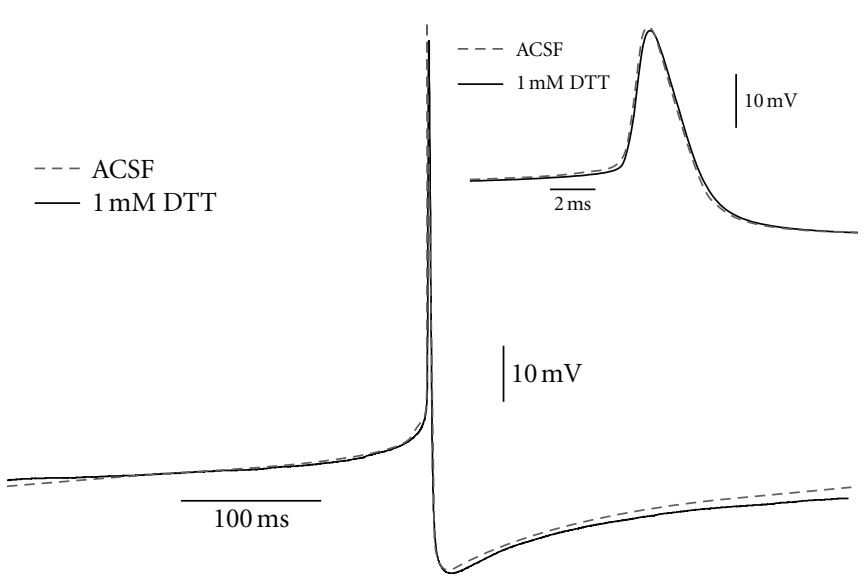

(b)

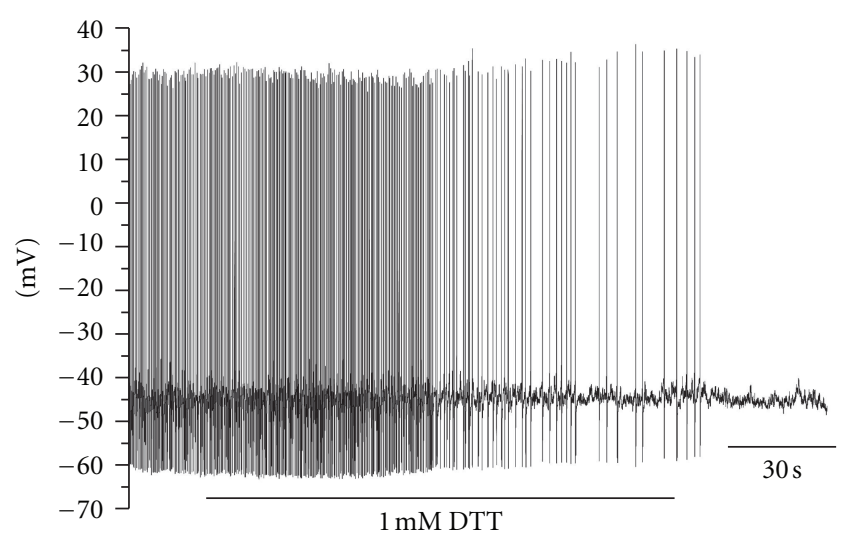

(d)

FIGURE 3: Impact of DTT treatment in the pacemaker process of LC neurons. (a) Table demonstrating the effect of $1 \mathrm{mM}$ DTT in the spontaneous firing of LC neurons and comparison of values obtained for AP before (ACSF) and $180 \mathrm{~s}$ after $1 \mathrm{mM} \mathrm{DTT}$ treatment $(n=19$ for spontaneous firing and $n=28$ for AP comparison). (b) Averaged APs demonstrating comparison before (ACSF) and after $180 \mathrm{~s}$ after $1 \mathrm{mM}$ DDT treatment $(n=28)$. Hyperpolarizing group was excluded from comparison demonstrated in (a) and (b) due to lack of APs at $180 \mathrm{~s}$ treatment. (c) and (d), Example for recordings demonstrating the two minor effects induced by 1 mM DTT where neurons hyperpolarized and ceased firing (c) and stopped firing without hyperpolarization (d) $(n=19)$.

those for Trolox application. Application of depolarizing ramps to 9 LC neurons indicated that 7 exhibited a large inward current at depolarized potentials with minimal if any initial outward current, and 2 neurons exhibited only outward currents (Figures 4(a) to 4(c)). Voltage step protocols applied to further 10 LC neurons produced the same characteristic depolarization-induced responses with 5 exhibiting inward and 5 exhibiting outward differential currents (Figures $4(\mathrm{~d})$ to $4(\mathrm{f})$ ). The size of the currents induced by both voltage ramp and step protocols during DTT treatment was larger than the currents induced by Trolox treatment (compare Figures 2(c) and 2(f) with Figures 4(c) and 4(f)).

\subsection{Effect of Trolox and DTT Cotreatment with the Mitochon-} drial Protonophore CCCP during Ramp-Elicited Currents. We next investigated a role of mitochondria in the antioxidant actions as these organelles are the main source of reactive oxygen species in neurons and also play an important role in
$\mathrm{Ca}^{2+}$ buffering [21]. To do this, we perturbed mitochondrial metabolism using the mitochondrial protonophore carbonyl cyanide m-chlorophenylhydrazone (CCCP) without and with cotreatment with Trolox or DTT.

Ramp protocols were used as they can reveal voltagedependent currents, including those that flow during the interspike interval [16]. CCCP $(1 \mu \mathrm{M})$ induced an initial differential outward (up to $\sim-20 \mathrm{mV}$ ) followed by an inward current during the ramp depolarization (Figure 5). Cotreatment with Trolox $(100 \mu \mathrm{M})$ caused a small reduction in the CCCP-induced differential outward current between membrane potentials $\sim-40 \mathrm{mV}$ to $\sim-30 \mathrm{mV}$ (Figure 5(a)). DTT cotreatment in contrast had a more profound impact on the CCCP-induced differential outward current. It partially reversed the outward current and reduced it to less than half at its peak (Figure 5(b)). DTT co-treatment also shifted the reversal potential from $\sim 80 \mathrm{mV}$ to $\sim-60 \mathrm{mV}$, suggesting recruitment of different channels and/or modulation of the channel's selectivity to ions. These results 


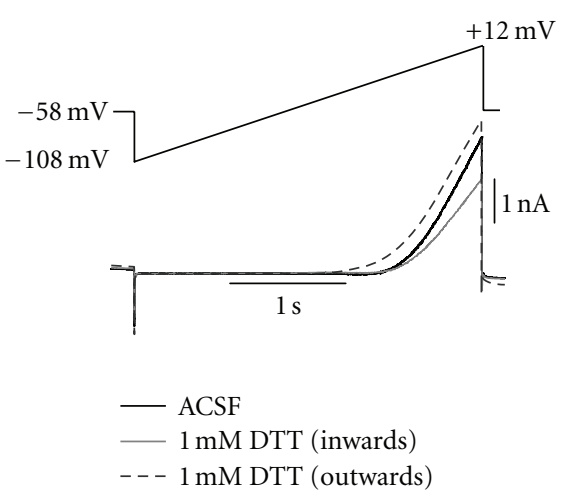

(a)

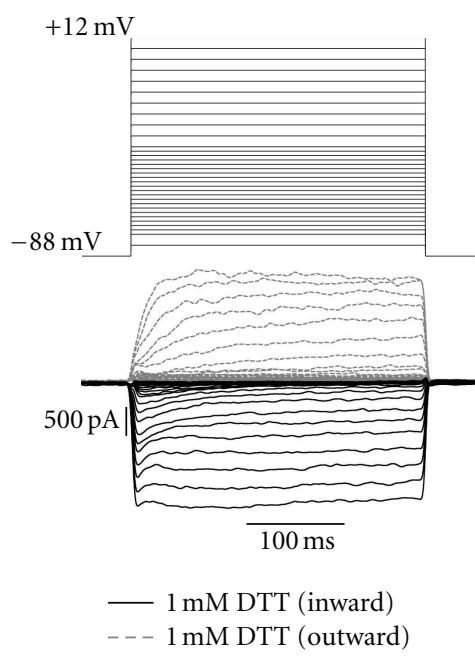

(d)

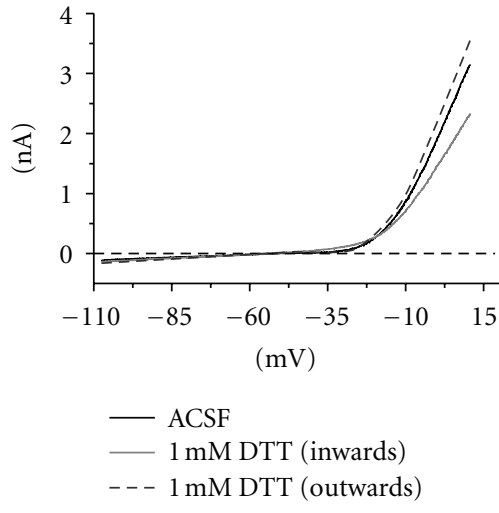

(b)

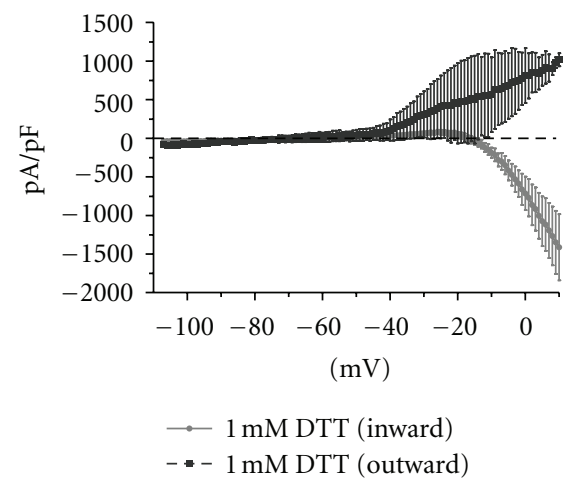

(c)

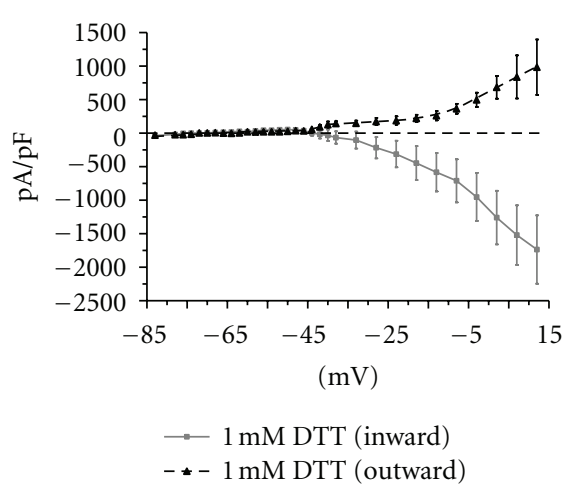

(f)

FIGURE 4: Effect of DTT treatment on voltage-dependent currents evoked by ramps and pulses. (a) Representative recording of the currents evoked by depolarizing ramps showing the current evoked in ACSF (control solution; solid black line) and the inward (solid light grey) and outward (dashed grey) currents evoked at $180 \mathrm{~s}$ after $1 \mathrm{mM} \mathrm{DTT}$ application $(n=9)$ ). (b) $I$ - $V$ plot for the currents presented in a. (c) Mean differential (i.e., DTT-control) with records obtained $180 \mathrm{~s}$ after rapid application of DTT showing the inward (solid light grey, 7 of 9 neurons) and outward (dashed grey, 2 of 9 neurons) currents. (d), (e), and (f) were performed in $1 \mu \mathrm{M}$ TTX background. (d) Representative depolarizing pulse-evoked differential currents obtained by taking the currents in test solution (i.e., $1 \mathrm{mM} \mathrm{DTT}+1 \mu \mathrm{M}$ TTX) and subtracting the corresponding currents in control (i.e., $1 \mu \mathrm{M}$ TTX) $180 \mathrm{~s}$ after DTT application. (e) Averaged $I-V$ plot showing the currents evoked by pulses for control ( $1 \mu \mathrm{M}$ TTX — solid black) and the inward (solid light grey) and outward (dashed grey) currents after $180 \mathrm{~s}$ of $1 \mathrm{mM}$ DTT application.(f) Mean differential $I-V$ plots (i.e., DTT-TTX) inward (solid light grey, 5 of 10 neurons) and outward (dashed grey, 5 of 10 neurons) after $180 \mathrm{~s}$ application of 1 mM DTT. Graph shows mean \pm SEM with $n=10$ for (d), (e), and (f).

suggest that the antioxidants Trolox and DTT can affect mitochondrial function either directly or by altering existing neuronal free radicals.

\subsection{Impact of Trolox and DTT Treatment on Cytosolic $\mathrm{Ca}^{2+}$} and Mitochondrial Membrane Potential under Control Conditions and When Mitochondrial Function Is Impaired. Due to the heterogeneous nature of the responses produced by the two antioxidant treatments, we next investigated if the activation of different currents was related to the cytosolic $\mathrm{Ca}^{2+}$ concentration $\left(\left[\mathrm{Ca}^{2+}\right]_{c}\right)$ in both control conditions and those where mitochondrial function was impaired. Figure 6(a) demonstrates that under control conditions, neither Trolox or DTT treatments were able to increase $\left[\mathrm{Ca}^{2+}\right]_{c}$, suggesting that $\mathrm{Ca}^{2+}$-activated pathways are not involved in the induction/modulation of ionic currents by these antioxidants. When CCCP was added to impair mitochondrial function, Trolox $(100 \mu \mathrm{M})$ caused a further enhancement of the CCCP-induced increase in $\left[\mathrm{Ca}^{2+}\right]_{c}$ (Figure 6(b)). In contrast, cotreatment with DTT $(1 \mathrm{mM})$ had no impact on the CCCP-induced increase in $\left[\mathrm{Ca}^{2+}\right]_{c}$ (Figure 6(b)). The consequences of the Trolox-induced increase in $\left[\mathrm{Ca}^{2+}\right]_{c}$ are unclear given that Trolox was less effective than DTT in modulating CCCP-related voltage dependent currents (Figure 5(a)).

Given that mitochondrial function is generally dependent on mitochondrial membrane potential $(\Psi \mathrm{m})$ [22], we 


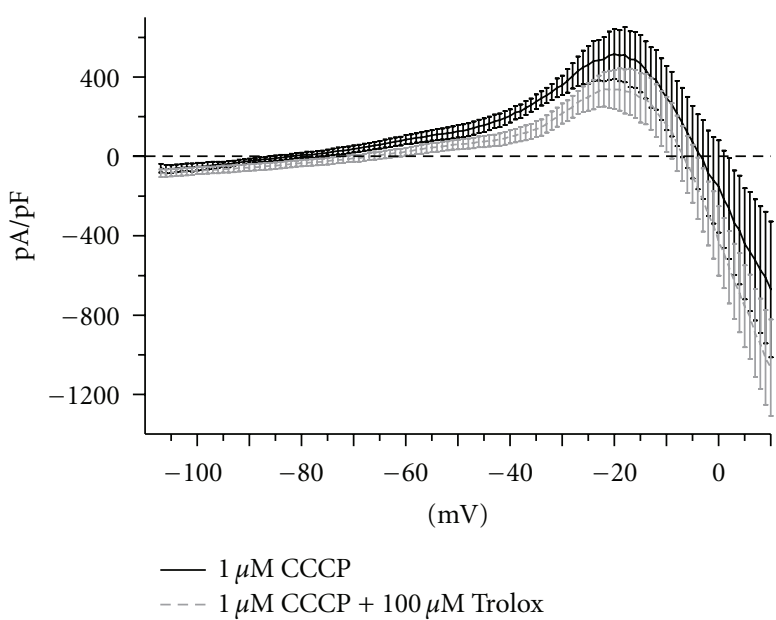

(a)

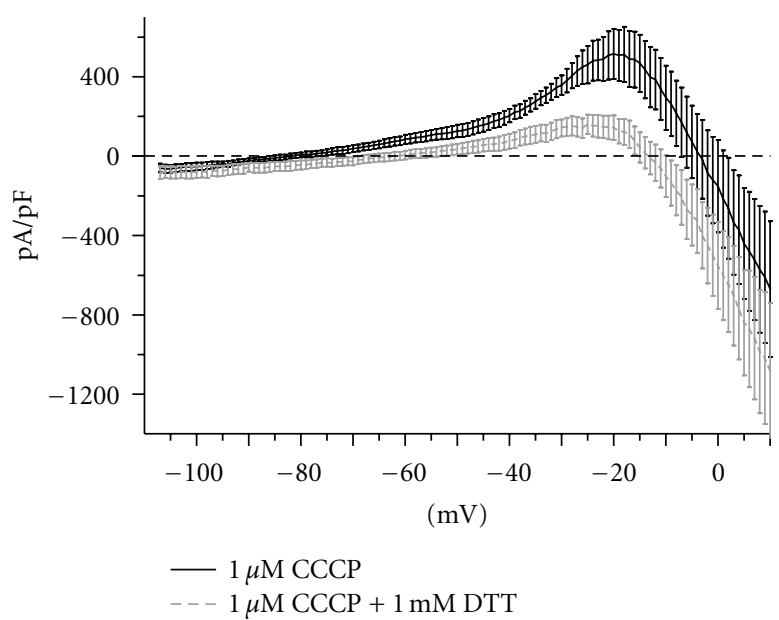

(b)

FIgURE 5: Effect of Trolox and DTT treatment on ramp-evoked currents when mitochondrial membrane potential was impaired with CCCP. (a) and (b), Mean differential $I$ - $V$ plots (i.e., Antioxidants-control) demonstrating the impact of $100 \mu \mathrm{M}$ Trolox (a) and $1 \mathrm{mM}$ DTT (b) cotreatments with $1 \mu \mathrm{M}$ CCCP. Graph shows mean \pm SEM with $n=13$ for (a) and $n=6$ for (b).

investigated whether antioxidant treatments were able to modulate $\Psi \mathrm{m}$. Application of CCCP $(1 \mu \mathrm{M})$ reduced $\Psi \mathrm{m}$ (Figure $6(\mathrm{c}))$. Trolox $(100 \mu \mathrm{M})$ or DTT $(1 \mathrm{mM})$ also reduced $\Psi \mathrm{m}$ to an extent that was indistinguishable from that produced by impairing mitochondrial function with CCCP alone (Figure 6(c)). Application of the antioxidants together with CCCP appeared to be synergistic as it caused a profound decrease $\Psi \mathrm{m}$, with the effect of being most pronounced for DTT where a $\sim 70 \%$ reduction in $\Psi \mathrm{m}$ occurred (Figure $6(\mathrm{c})$ ). Importantly, fluorescence levels partially recovered to the same levels after $10 \mathrm{~min}$ of washout for both antioxidants in control and/or impaired conditions (Figure 6(c)). Taken together, these results suggest that mitochondria could be involved in the currents induced by Trolox and DTT treatments, but such actions are unlikely to be dependent on $\left[\mathrm{Ca}^{2+}\right]_{c}$.

\section{Discussion}

Many neuronal populations in the CNS are spontaneously active, including nuclei such as the LC and Substantia nigra (SN) $[23,24]$. Such sustained AP firing is tightly controlled and, given that nuclei such as the LC project widely over the brain [25], has major implications for brain function.

Free radicals and oxidative stress are known to be involved in the initiation and/or progression of a variety of neurological conditions, such as Alzheimer's and Parkinson's diseases [26-28], and disturbances in mitochondrial metabolism seem to be a key event in the occurrence of such pathologies [29]. Here, we demonstrate that antioxidant treatment of LC neurons, a neuronal population that is suggested to be involved in progression of many neurological diseases $[30,31]$, produced a heterogeneous response on the pacemaking activity in these neurons. Our results indicate that within the LC there is a subpopulation of neurons, which are more sensitive to free radical content and consequent modulation of the pacemaker activity. This opens the possibility that this neuronal subpopulation is particularly vulnerable and likely to undergo apoptosis or necrosis during the onset of specific neurological diseases.

The LC is the largest concentration of noradrenergic neurons in the brain, and it projects to and releases noradrenaline across a multitude of brain regions [32, 33]. LC neuron involvement in neurological pathologies, especially Parkinson's disease (PD), has been proposed because of the high levels of LC neuron degeneration observed in PD patients and because the LC plays a fundamental role in the early stages of the disease $[31,34]$. Further support for this hypothesis is provided by the fact that lesions to LC neurons increase the sensitivity of $\mathrm{SN}$ neurons to a range of insults $[35,36]$ and that simultaneous partial destruction of SN and LC neurons slows recovery in animal models of Parkinson's disease [30]. Furthermore, pharmacological stimulation of LC neurons imparts some resistance to $\mathrm{SN}$ neurons in animal models; Parkinson's disease [37] and genetically modified animals with increased noradrenergic innervation appear to be relatively immune to insults on SN neurons [38]. Therefore neuronal death in the LC may be a primary factor in the onset of PD with the consequent loss of noradrenergic signalling contributing to the loss of dopaminergic neurons in the SN. The fact that oxidative stress is one of the main causes of neuronal death in PD [39] makes the finding that there are subpopulations of LC neurons that are highly sensitive to free radicals of considerable interest.

Our results indicate that both Trolox and DTT induce heterogeneous responses in LC neuronal pacemaking (Figures 1-4), suggesting a differential sensitivity to antioxidants (or free radical content) in neuronal subpopulations within the LC. The majority of the neurons exhibited no detectable alteration in their firing rates (Figures $1(a)$ and $3(a)$ ). However, Trolox and DTT revealed two other responses and by 


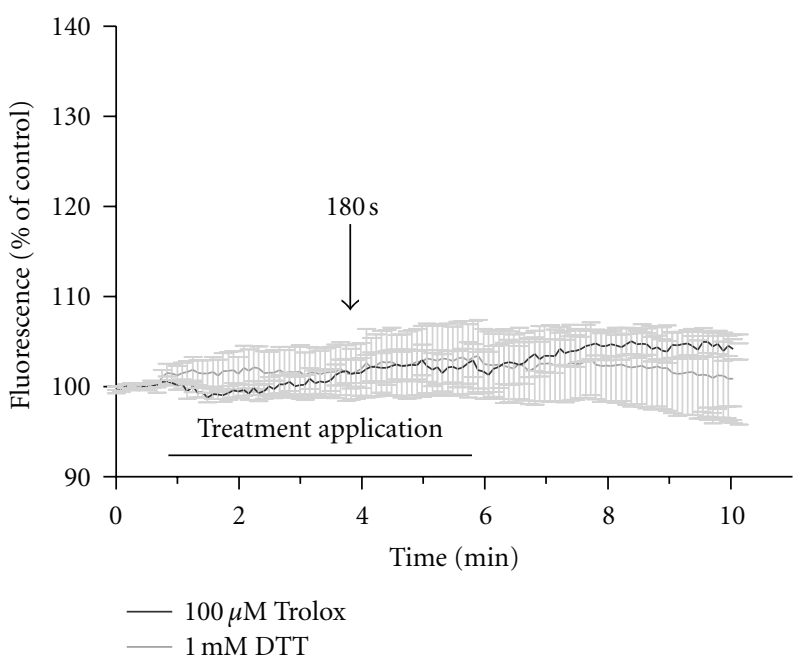

(a)

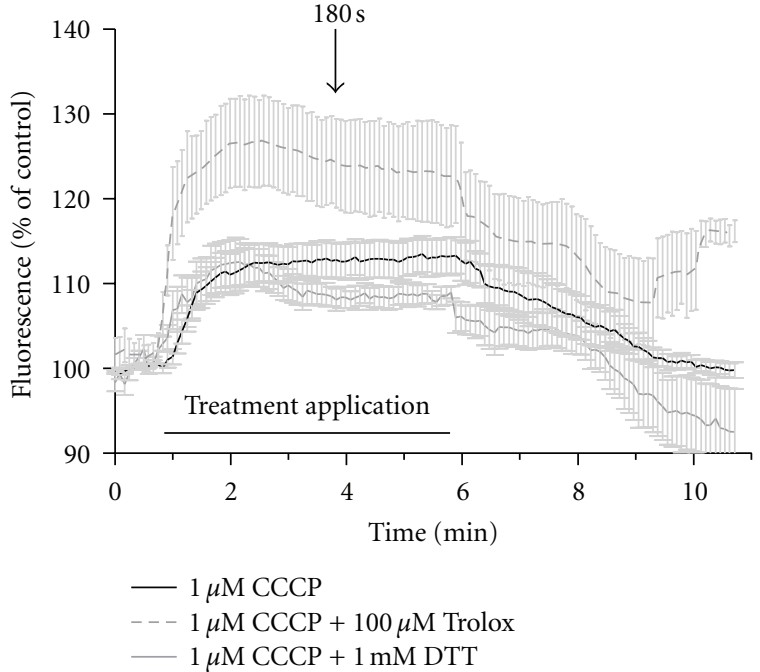

(b)

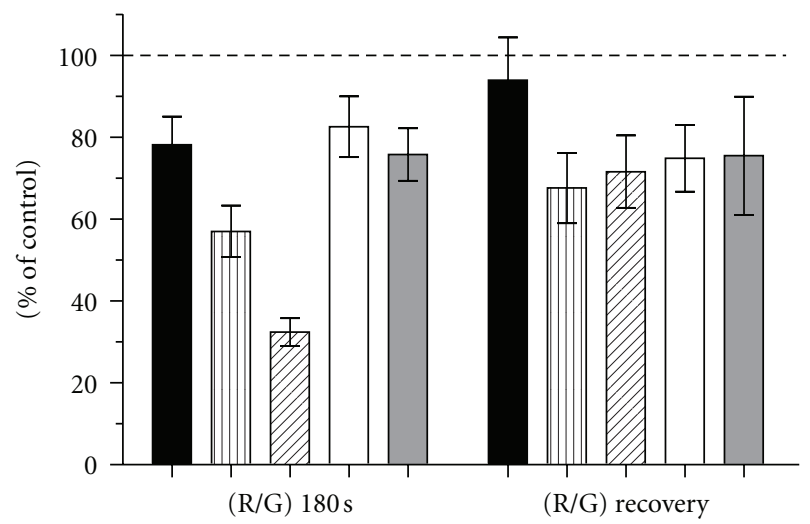

(\%)

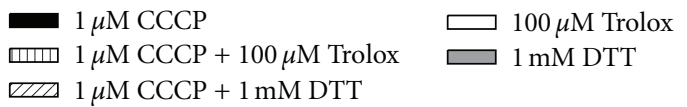

(c)

FIGURE 6: Effect of Trolox and DTT treatment in $\left[\mathrm{Ca}^{2+}\right]_{\mathrm{c}}$ and $\Psi \mathrm{m}$ in control and impaired conditions. (a) Graph demonstrating that both antioxidants did not impact on $\left[\mathrm{Ca}^{2+}\right]_{\mathrm{c}}$ in control conditions $(n=5$ for both). (b) Graph demonstrating that $100 \mu \mathrm{M}$ Trolox co-treatment with $1 \mu \mathrm{M}$ CCCP increased $\left[\mathrm{Ca}^{2+}\right]_{\mathrm{c}}$ and $1 \mathrm{mM}$ DDT did not effect the normal CCCP-induced increase in $\left[\mathrm{Ca}^{2+}\right]_{\mathrm{c}}(n=6$ for Trolox $n=5$ for DTT cotreatments, and $n=7$ for CCCP by itself). (c) JC- 1 fluorescence demonstrating the impact of Trolox and DTT in $\Psi \mathrm{m}$ in control and impaired ( $1 \mu \mathrm{M}$ CCCP cotreatment) conditions $(n=8$ for Trolox and $n=9$ for DTT by themselves; $n=12$ for Trolox and $n=10$ for DTT cotreatments; $n=9$ for CCCP by itself). All graphs show mean \pm SEM.

inference neuronal subpopulations: the first featured hyperpolarization and slowing down or cessation of pacemaking activity, whereas the second caused depolarization and an increase in firing rate (Figures 1 and 3). These observations are surprising given that LC neurons have generally been considered to be fairly homogeneous with respect to their electrophysiological properties, and previous results from our group detected no electrophysiological differences in the neuronal population on which our experiments were made $[14,16,40]$. Voltage clamp experiments confirmed the heterogeneity we observed in our experiments on LC neurons, as application of the antioxidants also revealed two types of responses when ramps or pulses were applied
(Figures 2 and 4). Another important finding came from our $\mathrm{Ca}^{2+}$ imaging experiments where, in contrast, application of antioxidants produced no change in $\left[\mathrm{Ca}^{2+}\right]_{\mathrm{c}}$ (Figure 6(a)). This suggests that the effects we observed were caused by changes in the neuronal free radical content and not by changes in $\left[\mathrm{Ca}^{2+}\right]_{c}$. Trolox treatment had a small impact on voltage-dependent currents (Figure 5(a)) however DTT treatment had a profound impact. DDT partially reversed the currents induced by CCCP coapplication (Figure 5(b)) and this effect was unlikely to be mediated by $\left[\mathrm{Ca}^{2+}\right]_{\mathrm{c}}$ (Figure 6(b)). A role for mitochondria was indicated as the antioxidants altered $\Psi \mathrm{m}$ when applied alone or combined with CCCP (Figure 6(c)). 
The finding of two neuronal subpopulations within LC that are responsive to antioxidant treatment may be of considerable importance for our understanding of the environment and physiological conditions that lead to development of neurological diseases. It is difficult to delineate which subpopulation will be most adversely affected by changes in free radical content. The subpopulation that responded to antioxidants with hyperpolarization will be protected by antioxidants, as pacemaking and hence firing rate would slow down or stop, thus saving energy and accelerating recovery time in cases of hypoxia [41]. Abolition of firing would also prevent activation of voltage-dependent $\mathrm{Ca}^{2+}$ channels and the subsequent increase in $\left[\mathrm{Ca}^{2+}\right]_{\mathrm{c}}$. This would slow activity in all $\mathrm{Ca}^{2+}$-dependent pathways.

Control of $\left[\mathrm{Ca}^{2+}\right]_{c}$ is of fundamental importance given apoptotic and/or necrotic pathways can be initiated by uncontrolled increases in $\left[\mathrm{Ca}^{2+}\right]_{c}[42,43]$. In contrast, the neuronal subpopulation where antioxidants produced depolarization and elevated firing rates would be stressed by such treatment. We do not know the mechanism whereby some cells respond with inward or outward currents following antioxidant application. However, if these actions were due to altering free radical content, then "mopping up" free radicals may not necessarily protect cells. Given that specific neurological pathologies have been associated with an increase in free radicals, then it highlights the fact that antioxidant treatments may need to be carefully evaluated.

In summary, our findings indicate that there is a small neuronal subpopulation within LC that responds to antioxidants, and, on the basis that this is caused by altering free radicals, members of this subpopulation may be more subject to apoptosis or necrosis. We believe that the results presented here represent an important step for our understanding of how free radicals contribute to neuropathologies (such as LC loss in Parkinson's diseases) and suggest that antioxidant therapies must be carefully evaluated before administration.

\section{Abbreviations}

ACSF: Artificial cerebrospinal fluid

AP: Action potential

$\left[\mathrm{Ca}^{2+}\right]_{\mathrm{c}}$ : Cytosolic $\mathrm{Ca}^{2+}$ concentration

CCCP: Carbonyl cyanide m-chlorophenyl

hydrazone

CNS: Central nervous system

DTT: Dithiothreitol

LC: $\quad$ Locus coeruleus

PD: Parkinson's disease

TTX: Tetrodotoxin

Vm: Membrane potential

Im: Mitochondrial membrane potential.

\section{Acknowledgments}

This work was supported by the National Health and Medical research Council of Australia and by the Hunter Medical Research Institute.

\section{References}

[1] B. Halliwell, "Free radicals, antioxidants, and human disease: curiosity, cause, or consequence?" Lancet, vol. 344, no. 8924, pp. 721-724, 1994.

[2] B. Halliwell, "Oxidative stress and neurodegeneration: where are we now?" Journal of Neurochemistry, vol. 97, no. 6, pp. 1634-1658, 2006.

[3] D. O. Keyser and B. E. Alger, "Arachidonic acid modulates hippocampal calcium current via protein kinase $\mathrm{c}$ and oxygen radicals," Neuron, vol. 5, no. 4, pp. 545-553, 1990.

[4] L. Annunziato, A. Pannaccione, M. Cataldi et al., "Modulation of ion channels by reactive oxygen and nitrogen species: a pathophysiological role in brain aging?" Neurobiology of Aging, vol. 23, no. 5, pp. 819-834, 2002.

[5] H. J. Wang, Y. L. Li, L. B. Zhang et al., "Endogenous reactive oxygen species modulates voltage-gated sodium channels in dorsal root ganglia of rats," Journal of Applied Physiology, vol. 110, no. 5, pp. 1439-1447, 2011.

[6] V. Di Matteo and E. Esposito, "Biochemical and therapeutic effects of antioxidants in the treatment of alzheimer's disease, parkinson's disease, and amyotrophic lateral sclerosis," Curr Drug Target Cns Neurol Disord, vol. 2, no. 2, pp. 95-107, 2003.

[7] E. Esposito, D. Rotilio, V. Di Matteo, C. Di Giulio, M. Cacchio, and S. Algeri, "A review of specific dietary antioxidants and the effects on biochemical mechanisms related to neurodegenerative processes," Neurobiology of Aging, vol. 23, no. 5, pp. 719735, 2002.

[8] F. Dal-Pizzol, F. Klamt, M. L. C. Frota, L. F. Moraes, J. C. F. Moreira, and M. S. Benfato, "Retinol supplementation induces dna damage and modulates iron turnover in rat sertoli cells," Free Radical Research, vol. 33, no. 5, pp. 677-687, 2000.

[9] D. P. Gelain, M. Cammarota, A. Zanotto-Filho et al., "Retinol induces the erk1/2-dependent phosphorylation of creb through a pathway involving the generation of reactive oxygen species in cultured sertoli cells," Cellular Signalling, vol. 18, no. 10, pp. 1685-1694, 2006.

[10] R. B. Oliveira, M. A. Bittencourt Pasquali, A. Z. Filho et al., "Can electrons travel through actin microfilaments and generate oxidative stress in retinol treated sertoli cell?" Molecular and Cellular Biochemistry, vol. 301, no. 1-2, pp. 33-45, 2007.

[11] M. Valko, D. Leibfritz, J. Moncol, M. T. D. Cronin, M. Mazur, and J. Telser, "Free radicals and antioxidants in normal physiological functions and human disease," International Journal of Biochemistry and Cell Biology, vol. 39, no. 1, pp. 4484, 2007.

[12] M. J. Davies, L. G. Forni, and R. L. Willson, "Vitamin e analogue trolox c. e.s.r. and pulse-radiolysis studies of free-radical reactions," Biochemical Journal, vol. 255, no. 2, pp. 513-522, 1988.

[13] K. S. Iyer and W. A. Klee, "Direct spectrophotometric measurement of the rate of reduction of disulfide bonds. the reactivity of the disulfide bonds of bovine-lactalbumin," Journal of Biological Chemistry, vol. 248, no. 2, pp. 707-710, 1973.

[14] R. B. de Oliveira, B. Graham, M. C. H. Howlett et al., "Ketamine anesthesia helps preserve neuronal viability," Journal of Neuroscience Methods, vol. 189, no. 2, pp. 230-232, 2010.

[15] B. A. Graham, A. M. Brichta, and R. J. Callister, "Pinch-current injection defines two discharge profiles in mouse superficial dorsal horn neurones, in vitro," Journal of Physiology, vol. 578, no. 3, pp. 787-798, 2007. 
[16] R. B. de Oliveira, M. C. H. Howlett, F. S. Gravina et al., "Pacemaker currents in mouse locus coeruleus neurons," Neuroscience, vol. 170, no. 1, pp. 166-177, 2010.

[17] N. Akaike and A. J. Moorhouse, "Techniques: applications of the nerve-bouton preparation in neuropharmacology," Trends in Pharmacological Sciences, vol. 24, no. 1, pp. 44-47, 2003.

[18] B. A. Graham, P. R. Schofield, P. Sah, T. W. Margrie, and R. J. Callister, "Distinct physiological mechanisms underlie altered glycinergic synaptic transmission in the murine mutants spastic, spasmodic, and oscillator," Journal of Neuroscience, vol. 26, no. 18, pp. 4880-4890, 2006.

[19] P. H. Barry, "Jpcalc, a software package for calculating liquid junction potential corrections in patch-clamp, intracellular, epithelial and bilayer measurements and for correcting junction potential measurements," Journal of Neuroscience Methods, vol. 51, no. 1, pp. 107-116, 1994.

[20] S. T. Smiley, M. Reers, C. Mottola-Hartshorn et al., "Intracellular heterogeneity in mitochondrial membrane potentials revealed by a j-aggregate-forming lipophilic cation jc-1," Proceedings of the National Academy of Sciences of the United States of America, vol. 88, no. 9, pp. 3671-3675, 1991.

[21] J. L. Werth and S. A. Thayer, "Mitochondria buffer physiological calcium loads in cultured rat dorsal root ganglion neurons," Journal of Neuroscience, vol. 14, no. 1, pp. 348-356, 1994.

[22] A. L. Lehninger, D. L. Nelson, and M. M. Cox, Lehninger Principles of Biochemistry, W. H. Freeman, New York, NY, USA, 2008.

[23] P. G. Guyenet and G. K. Aghajanian, "Antidromic identification of dopaminergic and other output neurons of the rat substantia nigra," Brain Research, vol. 150, no. 1, pp. 69-84, 1978.

[24] J. T. Williams, R. A. North, and S. A. Shefner, "Membrane properties of rat locus coeruleus neurones," Neuroscience, vol. 13, no. 1, pp. 137-156, 1984.

[25] O. Eschenko, H. C. Evrard, R. M. Neves, M. Beyerlein, Y. Murayama, and N. K. Logothetis, "Tracing of noradrenergic projections using manganese-enhanced MRI," NeuroImage, vol. 59, no. 4, pp. 3252-3265, 2012.

[26] J. D. Adams and I. N. Odunze, "Oxygen free radicals and parkinson's disease," Free Radical Biology and Medicine, vol. 10, no. 2, pp. 161-169, 1991.

[27] G. Benzi and A. Moretti, "Are reactive oxygen species involved in alzheimer's disease?" Neurobiology of Aging, vol. 16, no. 4, pp. 661-674, 1995.

[28] S. J. Chinta and J. K. Andersen, "Redox imbalance in parkinson's disease," Biochimica Et Biophysica Acta, vol. 1780, no. 11, pp. 1362-1367, 2008.

[29] W. D. Parker, J. K. Parks, and R. H. Swerdlow, "Complex i deficiency in parkinson's disease frontal cortex," Brain Research, vol. 1189, no. 1, pp. 215-218, 2008.

[30] G. Bing, Y. Zhang, Y. Watanabe, B. S. McEwen, and E. A. Stone, "Locus coeruleus lesions potentiate neurotoxic effects of mptp in dopaminergic neurons of the substantia nigra," Brain Research, vol. 668, no. 1-2, pp. 261-265, 1994.

[31] M. Gesi, P. Soldani, F. S. Giorgi, A. Santinami, I. Bonaccorsi, and F. Fornai, "The role of the locus coeruleus in the development of parkinson's disease," Neuroscience and Biobehavioral Reviews, vol. 24, no. 6, pp. 655-668, 2000.

[32] L. W. Swanson, "The locus coeruleus: a cytoarchitectonic, golgi and immunohistochemical study in the albino rat," Brain Research, vol. 110, no. 1, pp. 39-56, 1976.
[33] S. L. Foote, F. E. Bloom, and G. Aston Jones, "Nucleus locus ceruleus: new evidence of anatomical and physiological specificity," Physiological Reviews, vol. 63, no. 3, pp. 844-914, 1983.

[34] L. S. Forno, "Neuropathology of parkinson's disease," Journal of Neuropathology and Experimental Neurology, vol. 55, no. 3, pp. 259-272, 1996.

[35] M. Mavridis, A. D. Degryse, A. J. Lategan, M. R. Marien, and F. C. Colpaert, "Effects of locus coeruleus lesions on parkinsonian signs, striatal dopamine and substantia nigra cell loss after 1-methyl-4-phenyl-1,2,3,6-tetrahydropyridine in monkeys: a possible role for the locus coeruleus in the progression of parkinson's disease," Neuroscience, vol. 41, no. 2-3, pp. 507-523, 1991.

[36] F. Fornai, L. Bassi, M. T. Torracca, V. Scalori, and G. U. Corsini, "Norepinephrine loss exacerbates methamphetamine-induced striatal dopamine depletion in mice," European Journal of Pharmacology, vol. 283, no. 1-3, pp. 99-102, 1995.

[37] F. Fornai, M. G. Alessandrì, M. T. Torracca, L. Bassi, V. Scalori, and G. U. Corsini, "Noradrenergic modulation of methamphetamine-induced striatal dopamine depletion," Annals of the New York Academy of Sciences, vol. 844, pp. 166177, 1998.

[38] M. R. Kilbourn, P. Sherman, and L. C. Abbott, "Reduced MPTP neurotoxicity in striatum of the mutant mouse tottering," Synapse, vol. 30, pp. 205-210, 1998.

[39] J. K. Andersen, "Oxidative stress in neurodegeneration: cause or consequence?” Nature Medicine, vol. 10, supplement, pp. S18-S25, 2004.

[40] R. B. de Oliveira, F. S. Gravina, R. Lim, A. M. Brichta, R. J. Callister, and D. F. van Helden, "Developmental changes in pacemaker currents in mouse locus coeruleus neurons," Brain Research, vol. 1425, pp. 27-36, 2011.

[41] K. Yamada, Juan Juan Ji, H. Yuan et al., "Protective role of atpsensitive potassium channels in hypoxia-induced generalized seizure," Science, vol. 292, no. 5521, pp. 1543-1546, 2001.

[42] I. I. Kruman and M. P. Mattson, "Pivotal role of mitochondrial calcium uptake in neural cell apoptosis and necrosis," Journal of Neurochemistry, vol. 72, no. 2, pp. 529-540, 1999.

[43] G. Szalai, R. Krishnamurthy, and G. Hajnóczky, "Apoptosis driven by ip3-linked mitochondrial calcium signals," EMBO Journal, vol. 18, no. 22, pp. 6349-6361, 1999. 


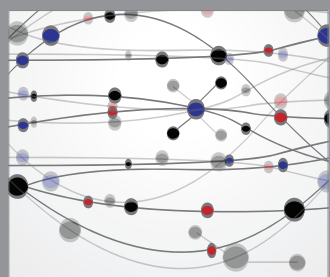

The Scientific World Journal
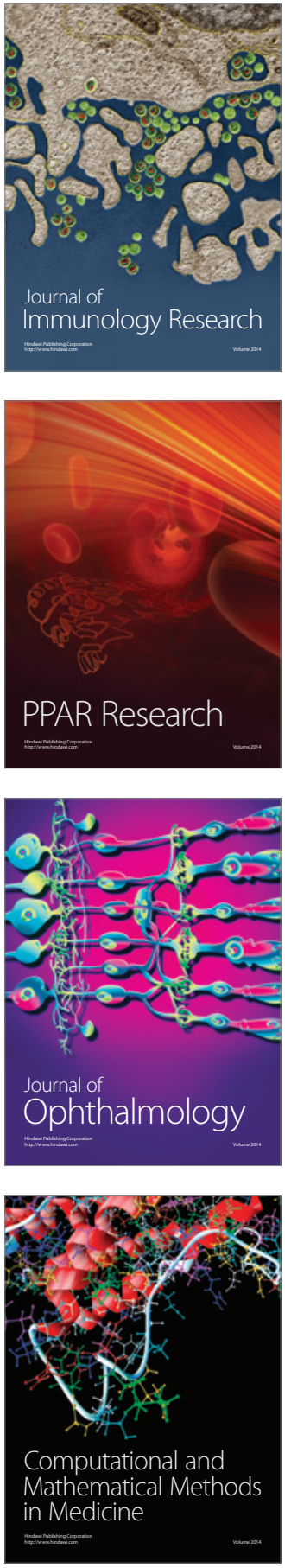

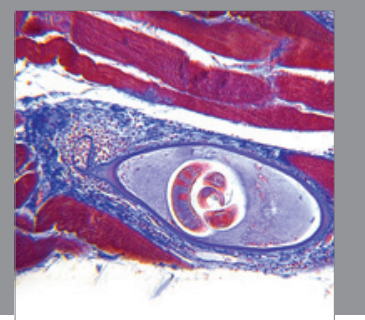

Gastroenterology

Research and Practice
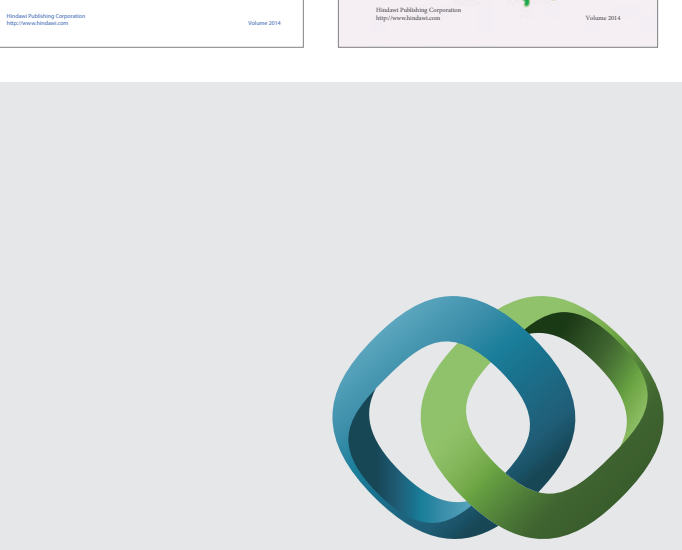

\section{Hindawi}

Submit your manuscripts at

http://www.hindawi.com
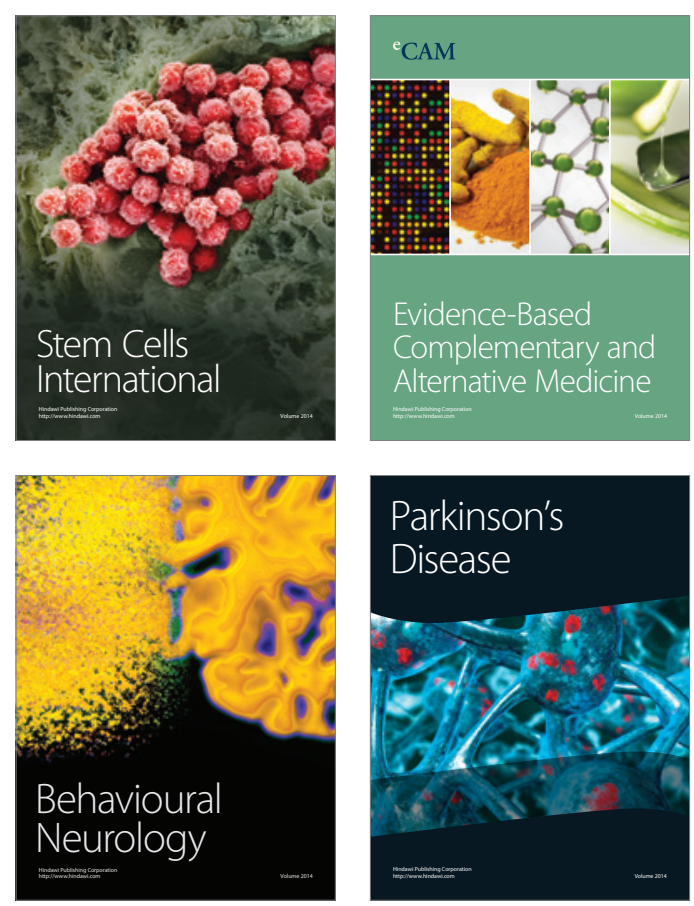

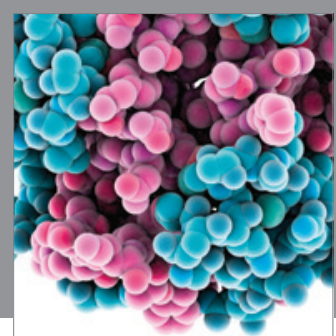

Journal of
Diabetes Research

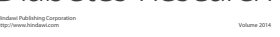

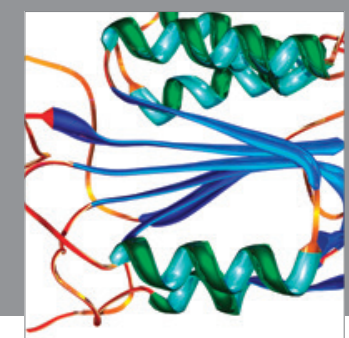

Disease Markers
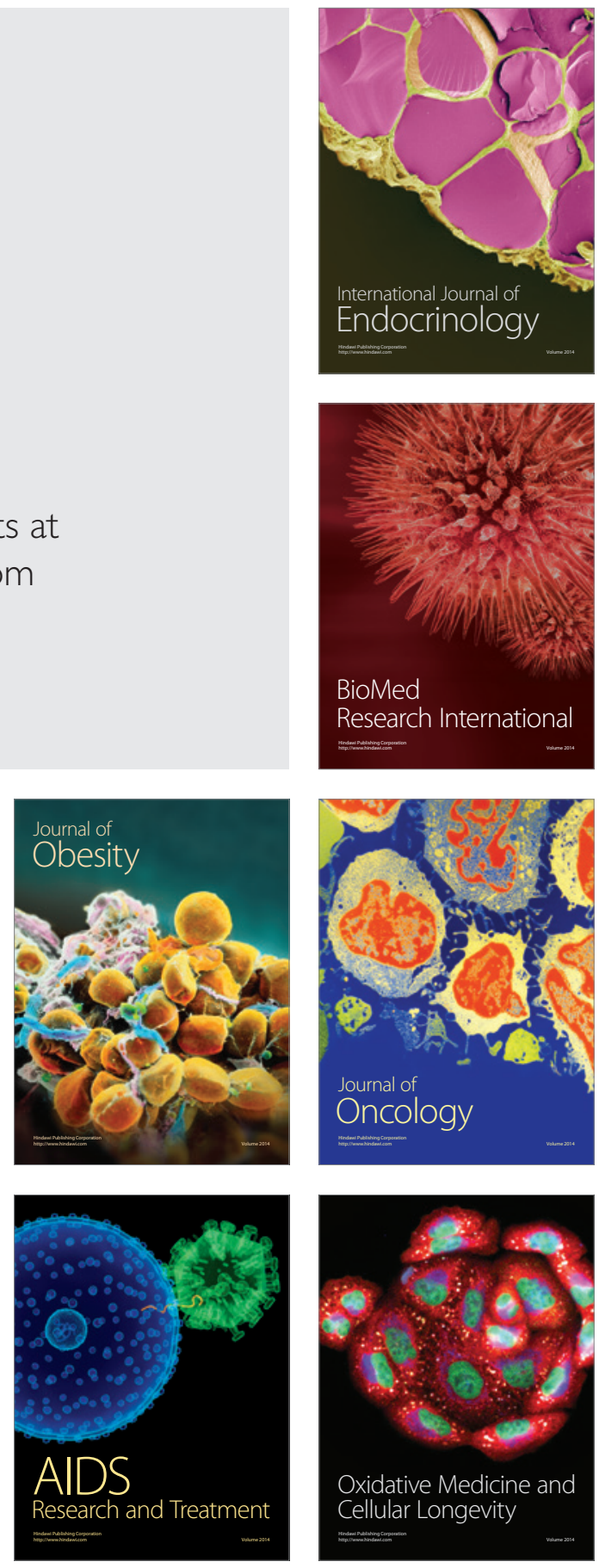